\title{
INVERSION POLYMORPHISM IN COMMON GREEN PIGEON, TRERON PHOENICOPTERA (LATHAM) (AVES)
}

\author{
HELAL AHMAD ANSARI AND DIPIKA KAUL \\ Department of Zoology, University of Allahabad, Allahabad-211 002, India
}

Received March 28, 1979

\begin{abstract}
The basic karyotype of common green pigeon, Treron phoenicoptera consists of seven pairs of macrochromosomes and thirty pairs of microchromosomes. In the population examined by us, there exists an interesting chromosomal polymorphism. Chromosomes 1 and 2 both exist in a dimorphic form. The dimorphism in each case appears to be due to the presence of a pericentric inversion. Chromosome 1 exists in $1^{m}$ and $1^{\text {st }}$ conditions and chromosome 2 in $2^{\text {st }}$ and $2^{m}$ conditions. The significance of this intrapopulation variation is discussed.
\end{abstract}

\section{INTRODUCTION}

Few natural populations of birds have been sampled extensively enough to know much about the occurrence of chromosomal polymorphisms and the part they may play in species evolution. Several reports of naturally occurring inversion polymorphisms in birds are on record (Thorneycroft 1966, 1975; Hammar 1970; Shields 1973, 1976; Hammar and Herlin 1975). Thorneycroft (1966) found population polymorphism for pericentric inversions involving chromosomes 2 and 3 in white-throated sparrow, Zonotrichia albicollis. A correlation between chromosomal type, phenotype and mating behaviour has been established in this bird (Thorneycroft 1975). An inversion polymorphism for chromosomes 2 and 5 is common to several geographically distributed species of juncos (Shields 1973, 1976). Here, the authors find no correlation between the chromosome morph type and phenotype.

We present here a case of inversion polymorphism in a population of common green pigeon, Treron phoenicoptera (Latham) belonging to the family Columbidae of the order Columbiformes.

\section{MATERIALS AND METHODS}

Three races of Treron phoenicoptera are recognized on the basis of size and details of colouration viz., T. p. phoenicoptera, the North Indian form, T. p. chlorigaster, the Peninsular form and $T . p$. phillipsi, the Ceylon race. $T$. p. phoenicoptera is the only race found around Allahabad where it is a resident bird common in occurrence. 
Mitotic metaphase preparations were obtained from colchicinized bone marrow cells of twelve adult individuals by the conventional flame drying technique. Morphometric analysis of the karyotypes was based on five well spread metaphase plates of each karyomorph of each sex. The system of Levan et al. (1964) was followed for the nomenclature of chromosomes and the partial karyotypes were arranged strictly according to the decreasing order of size.

Trypsin-Giemsa (G-) banding was obtained following the technique of Seabright (1972) and the constitutive heterochromatin staining technique of Au et al. (1975) was employed for the specific identification of the $W$ chromosome.

\section{RESULTS}

The bone marrow cells of six individuals of each sex yielded 186 well spread metaphase plates. The diploid chromosome number is found to be 74 in more than $50 \%$ of the cells examined.

Among the twelve individuals examined, three distinct karyotypes (disregarding the sex) were observed. It appears that the natural populations of this bird are polymorphic with respect to inversions in chromosome pairs 1 and 2 (Table 1). A description of the most commonly found doubly homozygous karyotype, which has been designated as the standard karyotype, is presented first followed by a brief description of the other two karyotypes.

Table 1. Percent relative lengths and centromeric indices of chromosomes $1^{m}, 1^{s t}, 2^{m}$ and $2^{s t}$ in the polymorphic population of $T$. phoenicoptera

\begin{tabular}{ccccc}
\hline Pair No. & Chrom. type & Rel. length & Centr. ind. & Remarks \\
\hline 1 & $m$ & 25.08 & 40.68 & Standard \\
& $s t$ & 25.14 & 19.40 & Inversion \\
2 & st & 19.09 & 15.62 & Standard \\
& $m$ & 18.43 & 38.63 & Inversion \\
\hline
\end{tabular}

\section{Standard karyotype $\left(1^{m} 1^{m}\right.$ and $\left.2^{s t} 2^{s t}\right)$}

Out of the twelve individuals four males and three females showed this homozyg. ous pattern. The seven pairs of largest macrochromosomes are sharply demarkated from the remaining thirty pairs of microchromosomes (Fig. $1 \mathrm{a}$ and b).

Chromosome 1 is the largest pair of the set. It is an $m$-chromosome and will be designated as chromosome $1^{m}$ hereafter. The second largest pair, chromosome 2 has its centromere in the subterminal region and will be designated as chromosome $2^{\text {st }}$. Chromosomes of the third pair have their centromeres in the terminal region. The fourth pair, a pair of metacentrics in the male, is identified as the $Z$ chromosome, since it is unpaired in the female cells where there is an unpaired sm-chromosome, smallest among the macrochromosomes. It is identified as the $W$ chromosome. In C-banded metaphase plates this element is totally heterochromatic (Fig. 2a). 


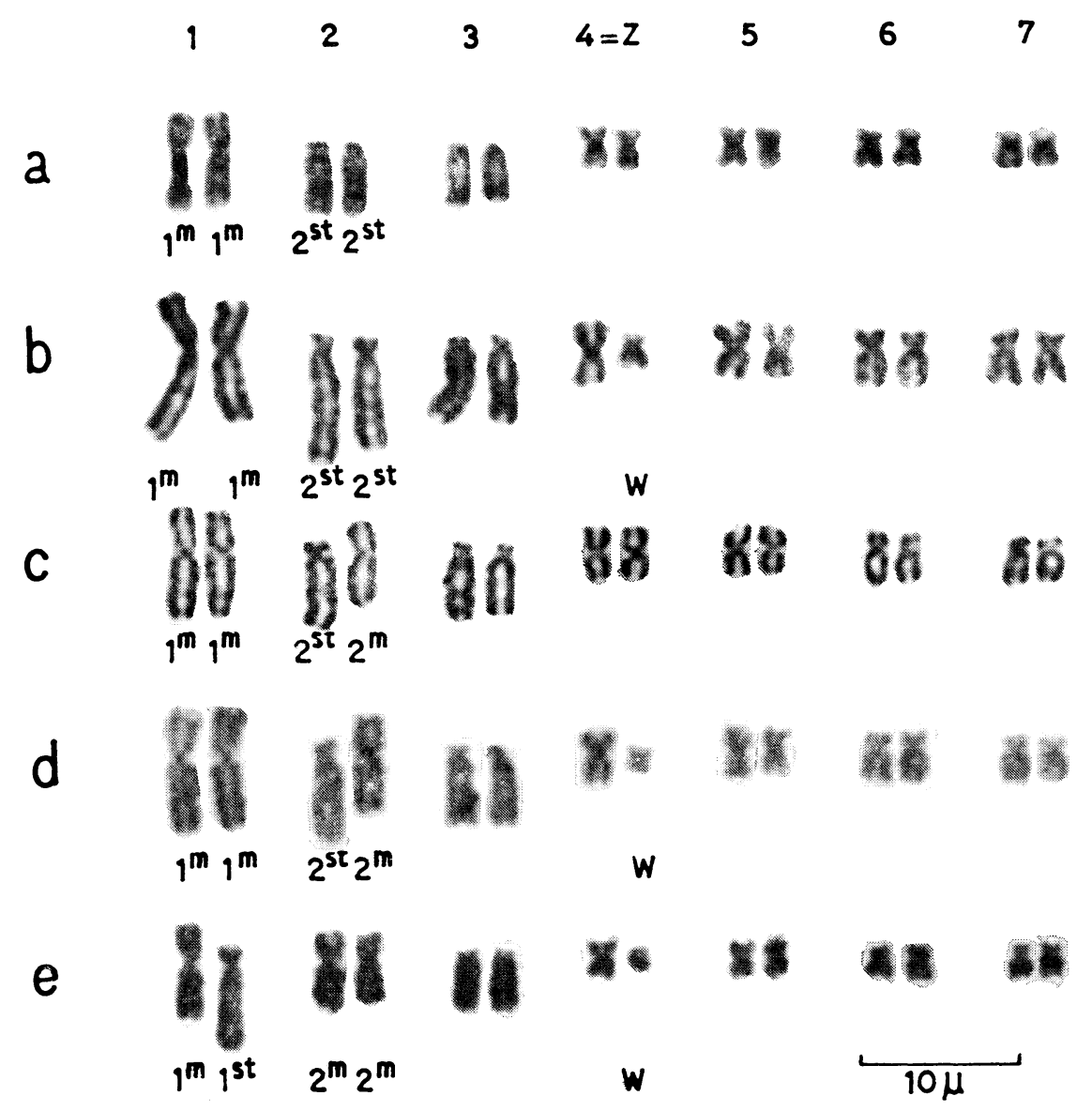

Fig. 1 a-e. Partial karyotypes of the different karyomorphs of $T$. phoenicoptera.

Chromosome 5 is an $m$-chromosome slightly smaller than the $Z$. In some plates it is difficult to distinguish between these two pairs. The last two pairs of macrochromosomes are $s m$-chromosomes. Remaining thirty pairs of microchromosomes comprise $45.15 \%$ of the total genome.

2. Karyotype of individuals homozygous for chromosome $1\left(1^{m} 1^{m}\right)$ and heterozygous for chromosome $2\left(2^{s t} 2^{m}\right)$

In four individuals (two males and two females) both the partners of chromosome 1 are of usual $m$ type comparable to the chromosome $1^{m}$ of the standard karyotype. However, only one partner of chromosome pair 2 has a centromeric index and relative length comparable to that of chromosome 2 of the standard karyotype, i. e., it is $2^{\text {st }}$. Its partner has a similar relative length but the position of the centromere is shifted. It is an $m$-type chromosome and is referred to as $2^{m}$. The rest of the karyotype is similar to the standard karyotype (Fig. $1 \mathrm{c}$ and d). The heterozygosity is strikingly apparent in G-banded metaphase plates (Fig. 2 b). 


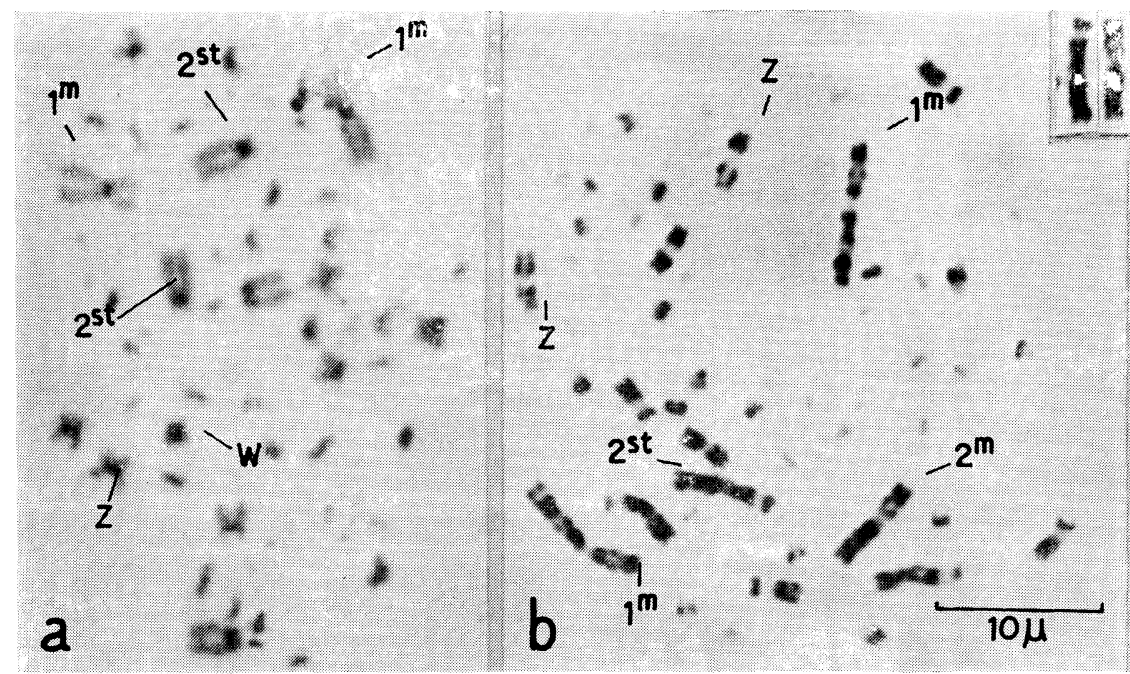

Fig. 2 a C-banded metaphase plate of the karyomorph $1^{m} 1^{m}, 2^{s t} 2^{s t}$ (female).

$2 \mathrm{~b}$ G-banded metaphase plate of the karyomorph $1^{m} 1^{m}, 2^{s t} 2^{m}$ (male). Heterozygous pair 2 in the inset.

3. Karyotype of individual heterozygous for chromosome $1\left(1^{m} 1^{\text {st }}\right)$ and homozygous for chromosome $2\left(2^{m} 2^{m}\right)$

A third karyotype is observed in a female individual where only one member of chromosome pair 1 is $1^{m}$ but the other is an st-type chromosome (Fig. $1 \mathrm{e}$ ). This is referred to as chromosome $1^{\text {st }}$. Another important variation in this karyotype is found in chromosome 2. Its relative length is comparable to that of chromosome 2 in other karyotypes and it is $2^{m} 2^{m}$ in morphology. The remaining chromosomes are like the standard karyotype.

\section{DISCUSSION}

Chromosomal polymorphism in this population of $T$. phoenicoptera can most reasonably be explained on the assumption of the occurrence of two independent pericentric inversions, one involving chromosome 1 and the other chromosome 2 . There are nine possible combinations of various chromosome morphs. In our small sample of twelve individuals collected from areas around Allahabad, six of the morphs are not at all represented. It is apparent from Table 1 that both for chromosome pairs 1 and 2, the relative lengths are constant but there is a significant shift in the centromeric index as one passes from one chromosome type to the other. These are the requirements to be met with if an inversion of a chromosomal segment has taken place. The evidence from G-banding (Fig. 2 b) further supports such a contention at least for chromosome 2.

The karyotype of $T$. phoenicoptera shows an overall resemblance to the karyotypes of pigeons of the genus Columba (Ohno et al. 1964; Galton and Bredbury 1966; 
Hammar 1966; Itoh et al. 1969; De Lucca and Aguiar 1976). In various Columba species, chromosomes 1 and 2 are $m$-type. If we assume that these represent the primitive condition, the $1^{\text {st }}$ and $2^{\text {st }}$ conditions may have been derived through two separate pericentric inversions. The condition $1^{m} 1^{m}$ is very common (found in 11 out of 12 individuals) while the condition $2^{m} 2^{m}$ has become rare. It would be too early to comment whether this is a case of a balanced polymorphism or of a transient polymorphism.

No correlation between the morphology of the birds and the chromosome morph type could be established. A clear picture of the significance of this polymorphism would emerge only after a thorough investigation of the meiotic mechanisms is carried out and extensive inter- and intrapopulation karyotypic data including banding patterns are available.

\section{ACKNOWLEDGMENTS}

We thank Prof. U.S. Srivastava, Head of the Zoology Department, University of Allahabad, for providing laboratory facilities and Prof. R. N. Shoffner, University of Minnesota, for the gift of GIBCO trypsin. Thanks are also due to the Director, Zoological Survey of India, for the identification of the specimens. This work has been supported by a grant from CSIR, India in the form of a Senior Research Fellowship to one of us (H. A. A.).

\section{LITERATURE CITED}

Au, W., N.S. Fechheimer, and S. Soukup, 1975 Identification of the sex chromosomes in the bald eagle. Canad. J. Genet. Cytol. 17: 187-191.

De Lucca, E. J., and M. L. R. De Aguiar, 1976 Chromosomal evolution in Columbiformes (Aves). Caryologia 29: 59-68.

Galton, M., and P.R. Bredbury, 1966 DNA replication patterns of the sex chromosomes of the pigeon (Columba livia domestica). Cytogenetics 5: 295-306.

Hammar, B., 1966 The karyotypes of nine birds. Hereditas 55: 367-385.

Hammar, B., 1970 The karyotypes of thirty-one birds. Hereditas 65: 29-58.

Hammar, B., and M. Herlin, 1975 Karyotypes of four species of the order Passeriformes. Hereditas 80: 177-184.

Itoh, M., T. Ikeuchi, H. Shimba, M. Mori, M. Sasaki, and S. Makino, 1969 A comparative karyotype study in fourteen species of birds. Japan. J. Genetics 44: 163-170.

Levan, A., K. Fredga, and A. A. Sandberg, 1964 Nomenclature for centromeric position on chromosomes. Hereditas 52: 201-220.

Ohno, S., C. Stenius, L. C. Christian, W. Becak, and M. L. Becak, 1964 Chromosoma (Berl.) 15: $280-288$.

Seabright, M., 1972 Use of proteolytic enzymes for the mapping of structural rearrangements on the chromosomes of man. Chromosoma (Berl.) 36: 204-210.

Shields, G.F., 1973 Chromosomal polymorphism common to several species of Junco (Aves). Canad. J. Genet. Cytol. 16: 461-471.

Shields, G.F., 1976 Meiotic evidence for pericentric inversion polymorphism in Junco (Aves). Canad. J. Genet. Cytol. 18: 747-751. 
Thorneycroft, H.B., 1966 Chromosomal polymorphism in the white-throated sparrow, Zonotrichia albicollis (Gmelin). Science 154: 1571-1572.

Thorneycroft, H. B., 1975 A cytogenetic study of the white-throated sparrow, Zonotrichia albicollis (Gmelin). Evolution 29: 611-621. 